Research Article

\title{
Study on Simulation of Stamping Process and Optimization of Process Parameters of Fender
}

\author{
Peng Wu $(\mathbb{D}$, Youming Wang $(\mathbb{D}$, and Peng Wan \\ School of Mechanical and Automotive Engineering, Anhui Polytechnic University, Wuhu, Anhui 241000, China \\ Correspondence should be addressed to Youming Wang; wymtlf@ahpu.edu.cn
}

Received 11 May 2019; Accepted 19 October 2019; Published 4 December 2019

Academic Editor: Fernando Lusquiños

Copyright (c) 2019 Peng Wu et al. This is an open access article distributed under the Creative Commons Attribution License, which permits unrestricted use, distribution, and reproduction in any medium, provided the original work is properly cited.

In order to obtain the optimum technological parameters of fender forming, the finite element analysis software DYNAFORM is used to simulate the drawing process of fender in this paper. The orthogonal test is designed and completed. On the basis of the orthogonal test, Taguchi method is used to design the orthogonal inner table, and the SNR of each factor at each level is calculated. The results of Taguchi method are analyzed with variance analysis, and the adjustable influencing variables and influence factors on quality stability that affect the forming quality of the fender are obtained. Experimental optimization of the adjustable variables is carried out again to obtain the optimal combination of process parameters that affect the shaping quality of the fender. The optimal combination of process parameters is as follows: blank holder force is $120 \mathrm{kN}$, model clearance is $1.0 \mathrm{t}$ (t represents sheet thickness), friction coefficient is 0.11 , and radius of die is $6 \mathrm{~mm}$. Finally, the experimental results show that the fender manufactured with this combination of process parameters has better performance.

\section{Introduction}

Automobile panels are important parts of automobile, most of them are formed by sheet metal stamping, which has the characteristics of complex shape, large structure size, and high surface quality requirements. The fender is a covering panel that is installed on the left and right sides of an automobile body to cover the wheels. Because the forming quality of fender plays an important role in vehicle collision performance, the forming quality of fender is relatively high [1]. Due to its deep drawing depth, complex shape, and other shape characteristics, it is relatively difficult to form. In the process of drawing forming, wrinkles, drawing breakage, springback, and other forming defects often occur.

Forming and process parameter optimization of automobile fender are studied by scholars. Liu et al. has used numerical simulation to analyze the forming process of automobile fender and improved the forming quality [2]. Ma have used AUTOFORM to simulate the stamping process of automobile fender and optimized the die structure [3]. Liu and Huang et al. have studied the forming performance of automobile fender by using DYNAFORM and compared the virtual testing die results with the actual testing die [4].
In this paper, the process parameters of the fender are optimized to design the fender that meets the requirements. The finite element analysis software DYNAFORM is used to simulate the forming of the fender. Levels and evaluation indexes are selected for orthogonal test. Taguchi method is used to optimize the forming parameters of the fender, and the optimal parameter combination of fender is obtained. The optimization analysis results are compared with the actual forming parts to provide basis for testing die and actual production.

\section{Analysis of Stamping Process of Fender}

An automobile fender model is shown in Figure 1. The stamping direction of the part is the vertical direction of the surface of the fender. When stamping, the upper die stamps down in the vertical direction as shown in Figure 1. Material of the part is DC04 and thickness is $0.5 \mathrm{~mm}$. The sheet size is $1315 \mathrm{~mm} * 1185 \mathrm{~mm} * 695 \mathrm{~mm}$.

The fender die is a single-acting stamping die with an inverted assembly mode. At the same time, the nitrogen cylinder installed on the punch can provide a relatively smooth and sufficient blank holder force to reduce safety risks. Relatively cheap HT300 is used as the main material of 


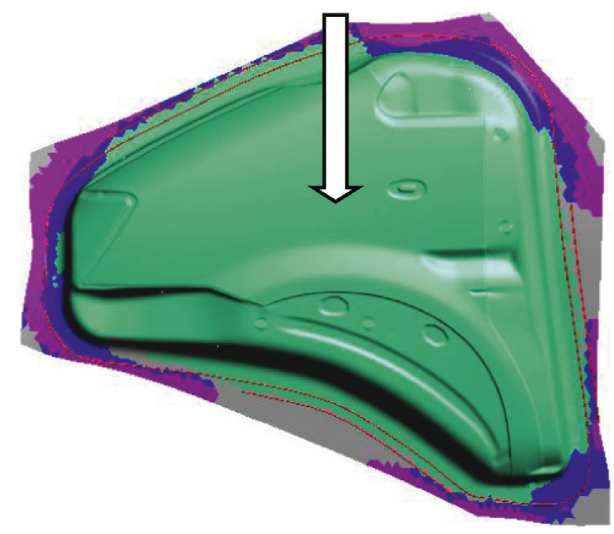

Figure 1: Fender model and stamping direction.

punch and concave dies, and direct waste disposal is adopted. According to the requirements of fender structure and punch strength, the guide structure of the blank holder is designed as inner guide. Die design requirements are as follows: when the punch and concave dies are pressed together, stiffeners shall be designed on the holder ring above the pad and the lower die seats below to prevent damage to the die. When there is no product on the binder surface, a gap of $2 \mathrm{~mm}$ should be set between the punch and concave dies [5].

The punch structure is the overall structure. In order to improve the working stability and running reliability of the punch in the stamping of plate parts, a mechanical fixing method is adopted [6]. Because the size of the mold is large and the forming surface is complex, the punch is enblock cast. There are grooves on the die to reduce the weight of the die. In order to fix the mould with the press machine, a $\mathrm{U}$-shaped groove is added in the direction of mould discharging. The 3D model of punch is shown in Figure 2. In the process of lifting the mold, the lower die holder bears the weight of the whole set of molds, and the strength of the lower die holder is very important, so the thickness of the lower die holder is $220 \mathrm{~mm}$. The structure and fixation of the concave die are the same as that of the punch. The 3D model of the concave die is shown in Figure 3.

\section{Simulation of Drawing Formality of Automobile Fender}

Blank Size Blank design module in the finite element analysis software DYNAFORM is used to design blank. The IGES 3D model is imported into DYNAFORM and then meshing. The shape and size of the blank are calculated from the part mold, and then, the appropriate shape of the blank is obtained through DYNAFORM simulation. The inflow resistance of material sheet can be adjusted and the stress distribution is improved when the upper die is pressed by selecting suitable draw-bead structure and arrangement, and the overall material flow speed of panels tends to be stable, so as to improve the forming quality of panels [7]. Through setting of DYNAFORM pretreatment, the thickness of the blank is set to $0.5 \mathrm{~mm}$, which is consistent with the actual sheet. Mesh parameters are shown in Table 1.

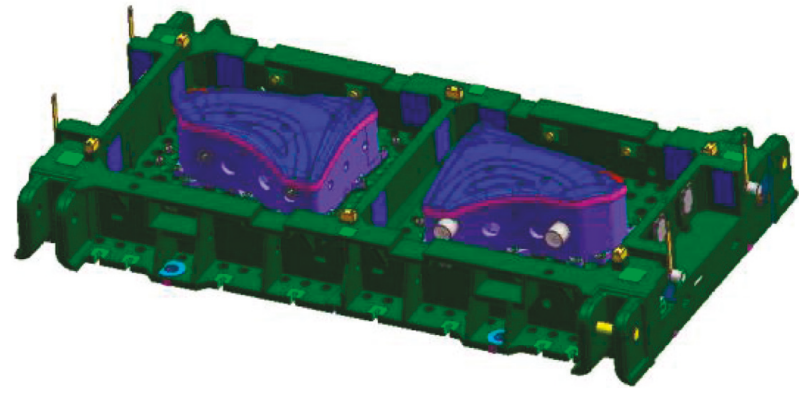

FIGURE 2: 3D model of punch.

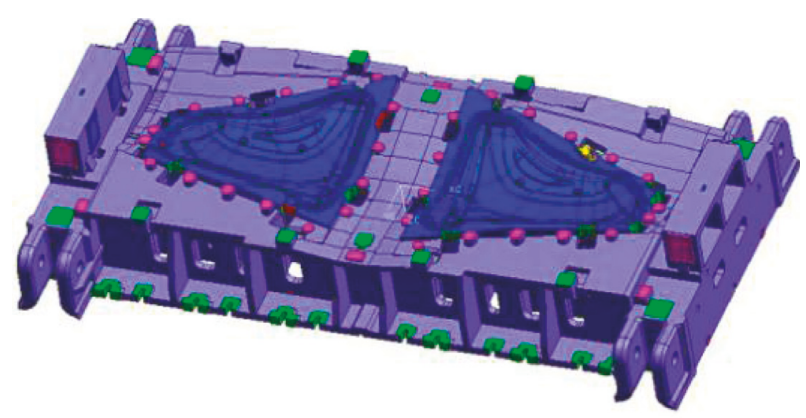

Figure 3: 3D model of the concave die.

TABLe 1: Parameters of mesh.

\begin{tabular}{lccccc}
\hline $\begin{array}{l}\text { Max. } \\
\text { size }\end{array}$ & $\begin{array}{c}\text { Min. } \\
\text { size }\end{array}$ & $\begin{array}{c}\text { Chordal } \\
\text { dev }\end{array}$ & Angle & $\begin{array}{c}\text { Gap } \\
\text { tolerance }\end{array}$ & $\begin{array}{c}\text { Ignore hole } \\
\text { size }\end{array}$ \\
\hline 20 & 0.5 & 0.05 & 10 & 0.5 & 0.00 \\
\hline
\end{tabular}

Automatic setting module in DYNAFORM software is adopted. Select flip compound die to create punch, blank holder, and other tools and generate blank mesh. DC04 in the material database is selected. The punch, concave die, blank holder, and other tools are defined according to the anisotropic sheet elasto-plastic material model. Set the initial blank holder force as $100 \mathrm{kN}$, die clearance as $0.9 \mathrm{t}$, friction coefficient as 0.11 , and radius of die as $6 \mathrm{~mm}$ and then start solving. The final-completed finite element simulation model of automobile fender drawing and forming is shown in Figure 4.

\section{Orthogonal Experimental Design of Fender Forming}

This paper selects blank holder force, mold clearance, friction coefficient, and radius of die as four factors influencing the orthogonal test [8]. The maximum thinning rate and maximum thickening rate are selected as evaluation indexes. The factors and level values selected by orthogonal test for the stamping forming of fender are shown in Table 2.

DYNAFORM is used to conduct stamping simulation for the 16 groups listed in the orthogonal table of the fender orthogonal test, and the simulation results are statistically analyzed. The orthogonal test data are shown in Table 3. 


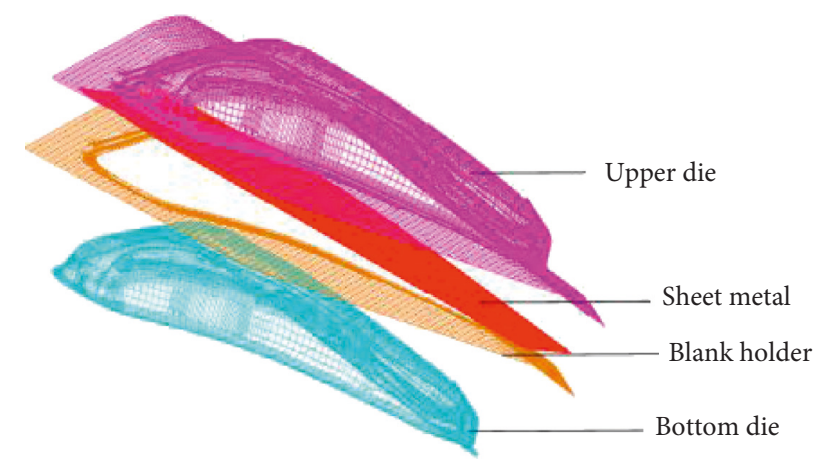

FIGURE 4: Finite element simulation model of automobile fender.

TABLE 2: Factors and level values in the orthogonal test.

\begin{tabular}{ccccc}
\hline & $\begin{array}{c}\text { Blank holder } \\
\text { force }(\mathrm{kN})\end{array}$ & $\begin{array}{c}\text { Model } \\
\text { clearance }\end{array}$ & $\begin{array}{c}\text { Friction } \\
\text { coefficient }\end{array}$ & $\begin{array}{c}\text { Radius of die } \\
(\mathrm{mm})\end{array}$ \\
\hline 1 & 90 & $0.9 \mathrm{t}$ & 0.11 & 6 \\
2 & 100 & $1.0 \mathrm{t}$ & 0.12 & 8 \\
3 & 110 & $1.1 \mathrm{t}$ & 0.13 & 10 \\
4 & 120 & $1.2 \mathrm{t}$ & 0.14 & 12 \\
\hline
\end{tabular}

For convenience, use A, B, C, and D to represent blank holder force, die clearance, friction coefficient, and fillet radius of die, respectively.

TABLE 3: Experimental data table of forward intersection of fender.

\begin{tabular}{lcccccc}
\hline $\begin{array}{l}\text { Test } \\
\text { number }\end{array}$ & $\begin{array}{c}\mathrm{A} \\
(\mathrm{kN})\end{array}$ & $\mathrm{B}$ & $\mathrm{C}$ & $\begin{array}{c}\mathrm{D} \\
(\mathrm{mm})\end{array}$ & $\begin{array}{c}\text { Maximum } \\
\text { thinning rate } \\
(\%)\end{array}$ & $\begin{array}{c}\text { Maximum } \\
\text { thickening } \\
\text { rate }(\%)\end{array}$ \\
\hline 1 & 90 & $0.9 \mathrm{t}$ & 0.11 & 6 & 20.29 & 12.67 \\
2 & 90 & $1.0 \mathrm{t}$ & 0.12 & 8 & 21.20 & 12.63 \\
3 & 90 & $1.1 \mathrm{t}$ & 0.13 & 10 & 27.09 & 7.48 \\
4 & 90 & $1.2 \mathrm{t}$ & 0.14 & 12 & 22.43 & 11.07 \\
5 & 100 & $0.9 \mathrm{t}$ & 0.12 & 10 & 27.30 & 8.59 \\
6 & 100 & $1.0 \mathrm{t}$ & 0.13 & 12 & 21.44 & 13.49 \\
7 & 100 & $1.1 \mathrm{t}$ & 0.14 & 6 & 21.92 & 10.20 \\
8 & 100 & $1.2 \mathrm{t}$ & 0.11 & 8 & 22.41 & 10.29 \\
9 & 110 & $0.9 \mathrm{t}$ & 0.13 & 8 & 22.34 & 11.33 \\
10 & 110 & $1.0 \mathrm{t}$ & 0.14 & 10 & 27.64 & 6.32 \\
11 & 110 & $1.1 \mathrm{t}$ & 0.11 & 12 & 21.71 & 11.76 \\
12 & 110 & $1.2 \mathrm{t}$ & 0.12 & 6 & 21.95 & 10.97 \\
13 & 120 & $0.9 \mathrm{t}$ & 0.14 & 12 & 22.62 & 9.98 \\
14 & 120 & $1.0 \mathrm{t}$ & 0.11 & 10 & 22.38 & 10.25 \\
15 & 120 & $1.1 \mathrm{t}$ & 0.12 & 8 & 22.85 & 11.42 \\
16 & 120 & $1.2 \mathrm{t}$ & 0.13 & 6 & 27.45 & 7.57 \\
\hline
\end{tabular}

According to the test results in Table 2, range $R$ values of various parameters are calculated and compared. Table 4 shows the influences of various factors on the maximum thinning rate. From Table 4, it can be observed that the influence rank of level factors on the maximum thinning rate is blank holder force $>$ mold clearance $>$ radius of die $>$ friction coefficient.

In Table $4, K 1, K 2, K 3$, and $K 4$, respectively, represent the sum of the maximum thinning rate of each factor under the influence of the first, second, third, and fourth levels, and $k$,
TABLE 4: Influence of various factors on maximum thinning rate.

\begin{tabular}{lcccc}
\hline & $\mathrm{A}$ & $\mathrm{B}$ & $\mathrm{C}$ & $\mathrm{D}$ \\
\hline$K 1$ & 139.03 & 144.07 & 145.28 & 149.12 \\
$K 2$ & 145.13 & 141.23 & 146.78 & 149.38 \\
$K 3$ & 139.82 & 140.13 & 148.52 & 149.51 \\
$K 4$ & 149.91 & 140.20 & 148.88 & 151.74 \\
$k 1=K 1 / 5$ & 27.91 & 29.11 & 29.74 & 30.12 \\
$k 2=K 2 / 5$ & 29.37 & 29.05 & 29.45 & 28.99 \\
$k 3=K 3 / 5$ & 29.26 & 28.11 & 29.12 & 29.82 \\
$k 4=K 4 / 5$ & 31.26 & 27.06 & 29.88 & 30.45 \\
$\mathrm{R}$ & 7.74 & 3.51 & 1.47 & 1.96 \\
Rank & 1 & 2 & 4 & 3 \\
\hline
\end{tabular}

$k 2, k 3$, and $k 4$, respectively, represent the mean value of the maximum thinning rate sum of each factor under the influence of the first, second, third, and fourth levels [9]. The range $R$ calculated shows the influence degree of various factors on the maximum thinning rate. Figure 5 shows the influence trend of various factors on the maximum thinning rate at different levels. According to evaluation index, the optimal combination of process parameters is A1B2C4D3. When the blank holder force is $90 \mathrm{kN}$, the die clearance is $1 \mathrm{t}$, the friction coefficient is 0.14 , and the radius of die is $10 \mathrm{~mm}$, the optimal maximum thinning rate can be obtained. In DYNAFORM, this parameter combination is used for stamping simulation test, and the maximum thinning rate under this condition is $20.11 \%$. By comparing with the experimental data of 16 groups of previous experiments, it can be found that the value is close to the minimum value in the orthogonal table.

According to the test results in Table 2, range $R$ values of various parameters are calculated and compared. Table 5 shows the influences of various factors on the maximum thickening rate. From Table 5, it can be observed that the influence rank of level factors on the maximum thickening rate is blank holder force $>$ friction coefficient $>$ mold clearance $>$ radius of die.

In Table $5, K 1, K 2, K 3$, and $K 4$ have the same meaning as in Table 4.

Figure 6 shows the influence trend of various factors on the maximum thickening rate at different levels. According to evaluation index, the optimal combination of process parameters is $\mathrm{A} 1 \mathrm{~B} 3 \mathrm{C} 2 \mathrm{D} 4$. When the blank holder force is $90 \mathrm{kN}$, the die clearance is $1 \mathrm{t}$, the friction coefficient is 0.13 , and the radius of die is $12 \mathrm{~mm}$, the optimal maximum thickening rate can be obtained. In DYNAFORM, this parameter combination is used for stamping simulation test, and the maximum thickening rate under this condition is $6.12 \%$. By comparing with the experimental data of 16 groups of previous experiments, it can be found that the value is close to the minimum value in the orthogonal table.

\section{Optimization of Stamping Process Parameters of Fender Based on Taguchi Method}

In the follow-up experiments, the quality characteristic is not taken as the index, but the SNR (signal-to-noise ratio) is 


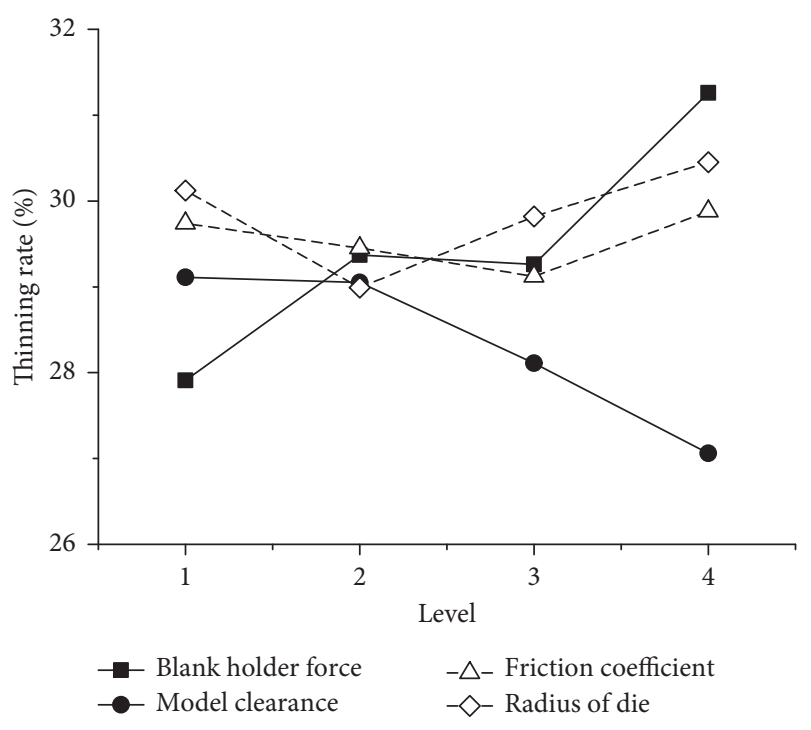

FIGURE 5: Influence trend of factors on the maximum thinning rate at different levels.

TABLE 5: Influence of various factors on maximum thickening rate.

\begin{tabular}{lcccc}
\hline & $\mathrm{A}$ & $\mathrm{B}$ & $\mathrm{C}$ & $\mathrm{D}$ \\
\hline$K 1$ & 324.34 & 389.00 & 275.65 & 328.17 \\
$K 2$ & 356.27 & 324.05 & 314.09 & 343.76 \\
$K 3$ & 377.68 & 346.12 & 329.52 & 312.75 \\
$K 4$ & 387.09 & 301.15 & 356.62 & 322.11 \\
$k 1=K 1 / 5$ & 65.47 & 78.80 & 56.53 & 67.13 \\
$k 2=K 2 / 5$ & 70.05 & 67.81 & 60.62 & 71.75 \\
$k 3=K 3 / 5$ & 71.54 & 69.16 & 65.50 & 66.55 \\
$k 4=K 4 / 5$ & 61.42 & 60.11 & 79.12 & 67.02 \\
$\mathrm{R}$ & 24.26 & 19.29 & 23.67 & 9.11 \\
Rank & 1 & 3 & 2 & 4 \\
\hline
\end{tabular}

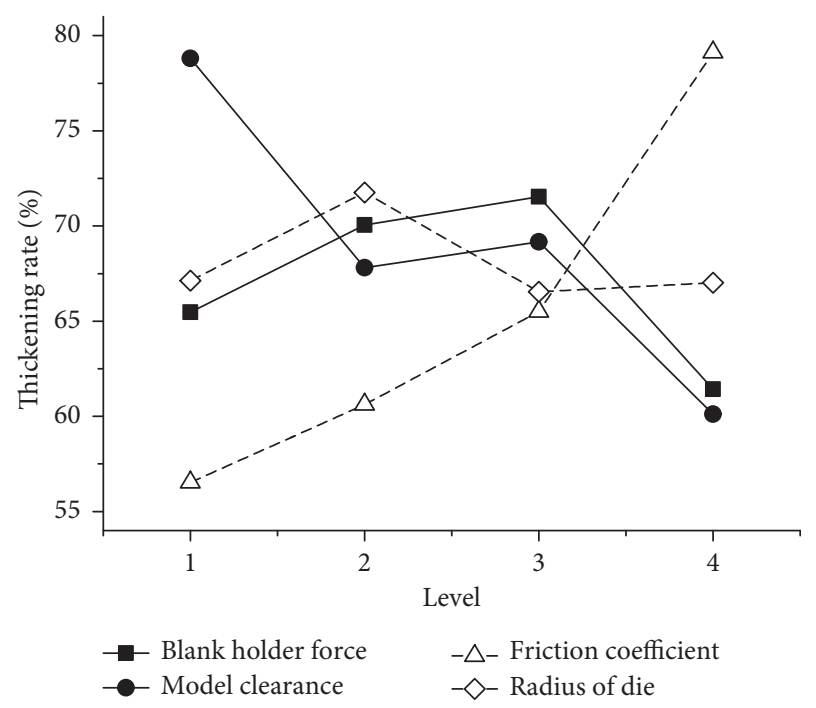

Figure 6: Influence trend of factors on the maximum thickening rate at different levels.

taken as the evaluation index [10]. Therefore, the interaction between factors at different levels is not taken as the object of study [11]. In this paper, the maximum thickening rate and the maximum thinning rate are used as the crinkling and cracking indexes [12]. In the actual stamping process, it is hoped that their values are as small as possible within a reasonable range, and the maximum thickening rate should be zero. This situation is called the low-value expectation property which is $Y_{i}$. The SNR is $\eta 1$ and its computation formula is

$$
\eta_{1}=-10 \log \frac{1}{n} \sum_{i=1}^{n} Y_{i}^{2}
$$

For the maximum thickening rate, the low-value expectation property is $Y_{j}$. The SNR is $\eta_{2}$ and its computation formula is

$$
\eta_{2}=-10 \log \frac{1}{n} \sum_{j=1}^{n} Y_{j}^{2}
$$

According to the influence degree of maximum thickening rate and maximum thinning rate on the forming quality of fender, therefore the $\eta_{1}$ coefficient is 0.3 and $\eta_{2}$ coefficient is 0.7 . The comprehensive SNR calculation formula is

$$
\eta=0.3 \eta_{1}+0.7 \eta_{2}
$$

The calculated results are shown in Table 6. According to the table, the maximum SNR value of group 14 is -23.7894, and the corresponding parameter combination is A4B2C1D3.

Calculate the sum $T$ of the comprehensive SNR:

$$
T=\sum_{i=1}^{16} \eta_{i}
$$

Calculate the sum of SNR $T_{i j}$ and mean value $t_{i j}$ of each factor at each level:

$$
T_{i j}=\sum_{n=1}^{4} \eta_{i j n}
$$

In the formula, $\mathrm{n}$ is four quantities of each level, $i$ is the four levels of each factor, and $j$ is factors A, B, C, and D.

Calculate the range $R$ for each factor:

$$
R=\eta_{\max }-\eta_{\min } .
$$

Calculate the sum of squared fluctuations $S_{T}$ of comprehensive SNR:

$$
\begin{aligned}
\bar{y} & =\frac{T}{16}, \\
S_{T} & =\sum_{n=1}^{n}\left(y_{i}-\bar{y}\right)^{2} .
\end{aligned}
$$

Calculate the sum of squared fluctuations $S_{j}$ of SNR of every factors:

$$
S_{i}=\frac{1}{4}\left(T_{1}^{2}+T_{2}^{2}+T_{3}^{2}+T_{4}^{2}\right)-\frac{1}{16} T^{2} .
$$

Enter all the above calculated data into Table 7. 
TABLE 6: The result of SNR calculation.

\begin{tabular}{lccccccc}
\hline Test number & $\mathrm{A}$ & $\mathrm{B}$ & $\mathrm{C}$ & $\mathrm{D}$ & $\eta_{1}$ & $\eta_{2}$ \\
\hline 1 & 90 & $0.9 \mathrm{t}$ & 0.11 & 6 & -26.1456 & -22.0555 & -24.1006 \\
2 & 90 & $1.0 \mathrm{t}$ & 0.12 & 8 & -26.3404 & -22.0418 & -24.1911 \\
3 & 90 & $1.1 \mathrm{t}$ & 0.13 & 10 & -27.2564 & -20.9806 & -24.1185 \\
4 & 90 & $1.2 \mathrm{t}$ & 0.14 & 12 & -27.1977 & -20.9564 & -24.0771 \\
5 & 100 & $0.9 \mathrm{t}$ & 0.12 & 10 & -27.5487 & -20.5868 & -24.0678 \\
6 & 100 & $1.0 \mathrm{t}$ & 0.13 & 12 & -27.4077 & -20.3763 & -23.8379 \\
7 & 100 & $1.1 \mathrm{t}$ & 0.14 & 6 & -27.3280 & -20.3477 & -23.8376 \\
8 & 100 & $1.2 \mathrm{t}$ & 0.11 & 8 & -27.2894 & -20.8109 & -24.0502 \\
9 & 110 & $0.9 \mathrm{t}$ & 0.13 & 8 & -27.2562 & -20.8422 & -24.0492 \\
10 & 110 & $1.0 \mathrm{t}$ & 0.14 & 10 & -27.4420 & -20.5406 & -23.9913 \\
11 & 110 & $1.1 \mathrm{t}$ & 0.11 & 12 & -27.3821 & -20.6270 & -24.0046 \\
12 & 110 & $1.2 \mathrm{t}$ & 0.12 & 6 & -27.0042 & -20.6420 & -23.8231 \\
13 & 120 & $0.9 \mathrm{t}$ & 0.14 & 12 & -27.0109 & -20.5947 & -23.8028 \\
14 & 120 & $1.0 \mathrm{t}$ & 0.11 & 10 & -27.0099 & -20.5686 & -23.7894 \\
15 & 120 & $1.1 \mathrm{t}$ & 0.12 & 8 & -27.0213 & -20.6102 & -23.8159 \\
16 & 120 & $1.2 \mathrm{t}$ & 0.13 & 6 & -27.1539 & -20.4717 \\
\hline
\end{tabular}

TABLE 7: Data statistics of SNR calculation results.

\begin{tabular}{lcccc}
\hline & A & B & C & D \\
\hline T1 & -96.4873 & -96.0204 & -95.9448 & -95.5741 \\
T2 & -95.7935 & -95.8097 & -95.8979 & -96.1064 \\
T3 & -95.8682 & -95.7766 & -95.8184 & -95.967 \\
T4 & -95.2209 & -95.7632 & -95.7088 & -95.7224 \\
$t 1$ & -24.1218 & -24.0051 & -23.9862 & -23.8935 \\
$t 2$ & -23.9484 & -23.9524 & -23.9745 & -24.0266 \\
$t 3$ & -23.9671 & -23.9442 & -23.9546 & -23.9918 \\
$t 4$ & -23.8052 & -23.9408 & -23.9272 & -23.9306 \\
Range (R) & 0.3166 & 0.0643 & 0.0590 & 0.1331 \\
Fluctuation (S) & 0.197 & 0.006 & 0.003 & 0.038 \\
\hline
\end{tabular}

Degree of freedom $f=$ number of levels of factors -1 , variance $V=$ sum of squared fluctuations/degrees of freedom, and $F$ test, $F=$ variance of factors/variance of error.

There is no error term in this test; therefore, the smallest $S_{3}$ is used as the sum of squared error fluctuations $S_{\mathrm{e}}$. Data analysis table is shown in Table 8 .

After calculating the SNR data in the range data analysis table, it can be known that factor A has very obvious influence on the quality fluctuation characteristics [13]. Therefore, the blank holder force can be confirmed as stable factor, and factors B, C, and D as adjustable factors. For stability factor A, its level is set as A4. The maximum thinning rate SNR of factors B, C, and D is listed in Table 9.

Since factors B, C, and D have little impact on the quality fluctuation characteristics, the maximum thickening rate can be ignored and the maximum thinning rate can be minimized by only adjusting parameters B, C, and D. According to Tables 7-9, when only the maximum thinning rate is considered, the optimal combination of process parameters is B2C1D1. Blank holder force is $120 \mathrm{KN}$, mold clearance is $1.0 \mathrm{t}$, friction coefficient is 0.11 , and radius of die $6 \mathrm{~mm}$.

Through the above analysis, the final optimal parameter combination is determined to be A4B2C1D1, which is basically consistent with the previous direct observation of the optimal parameter combination A4B2C1D3.
TABLE 8: Analysis table of variance data.

\begin{tabular}{lcccc}
\hline & $S$ & $f$ & $V$ & $F$ \\
\hline A & 0.197 & 3 & 0.0657 & 65.7 \\
B & 0.006 & 3 & 0.002 & 2 \\
C & 0.003 & 3 & & \\
D & 0.038 & 3 & 0.0127 & 1 \\
$S_{\mathrm{e}}$ & $(0.003)$ & $(4)$ & 0.001 & \\
$T$ & 0.244 & 16 & & \\
\hline
\end{tabular}

TABLE 9: SNR of maximum thinning rate of factors B, C, and D.

\begin{tabular}{lccc}
\hline Level & $\mathrm{B}$ & $\mathrm{C}$ & $\mathrm{D}$ \\
\hline 1 & -108.961 & -107.828 & -107.632 \\
2 & -108.200 & -107.915 & -107.907 \\
3 & -108.988 & -109.074 & -109.257 \\
4 & -108.645 & -108.979 & -108.998 \\
\hline
\end{tabular}

A4B2C1D1 parameter combination was used for simulation in DYNAFORM. The stamping simulation process diagram is shown in Figure 7, and the forming limit diagram is shown in Figures 8 and 9. As shown in Figures 8 and 9, it can be found that surface $A$ of the fender is all green, indicating that the stress distribution is uniform, the material feeding is stable, the maximum thinning rate and maximum thickening rate are moderate, and no wrinkling or cracking occurs. 

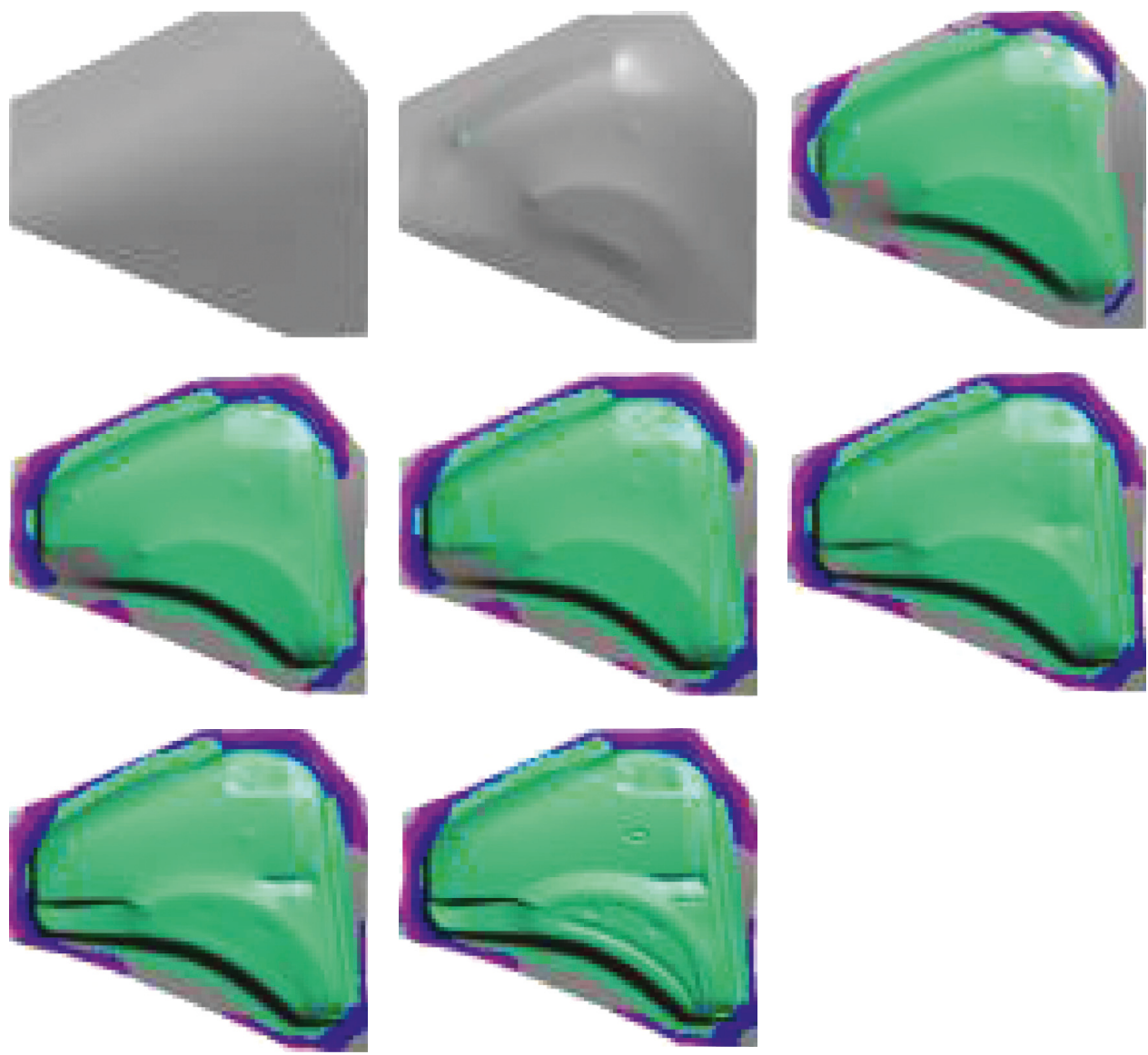

Figure 7: Fender forming process.

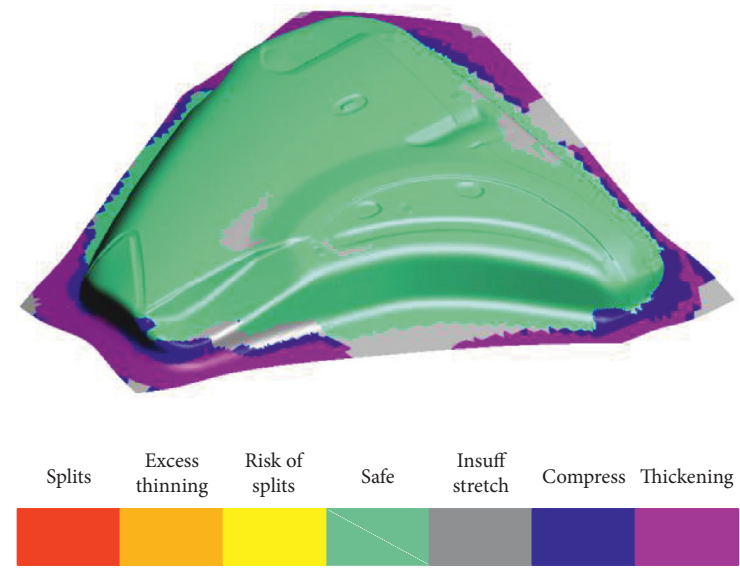

Figure 8: Thinning rate simulation result.

\section{Fender Performance Test}

Orthogonal test and Taguchi method optimization were carried out on the airfoil in the previous section. After optimization, the optimal combination of process parameters meeting the quality requirements is obtained [14]. Set the stamping parameters of the fender as follows: blank holder force is $120 \mathrm{KN}$, mold clearance is $1.0 \mathrm{t}$, friction coefficient is 0.11 , and radius of die $6 \mathrm{~mm}$. The fender products are shown in Figure 10. No cracking or wrinkling was found in the

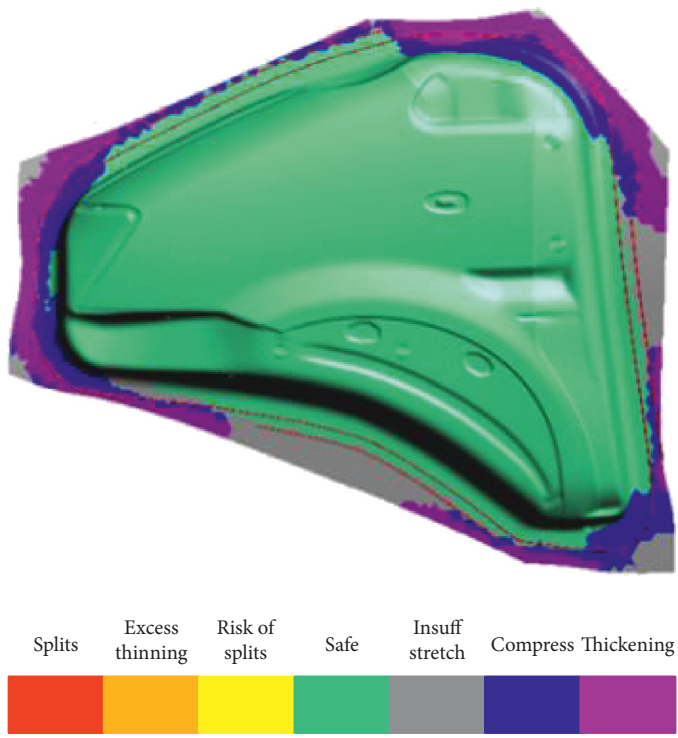

FIGURE 9: Thickening rate simulation result.

appearance of the fender, which indicated that the stamping parameters optimized by Taguchi method were reasonable.

In order to analyze the forming margin of the fender, the stamping product needs to be photographed by the camera in three coordinates first, and then, the photo is imported into the plate margin analysis software ARGUS for photo 


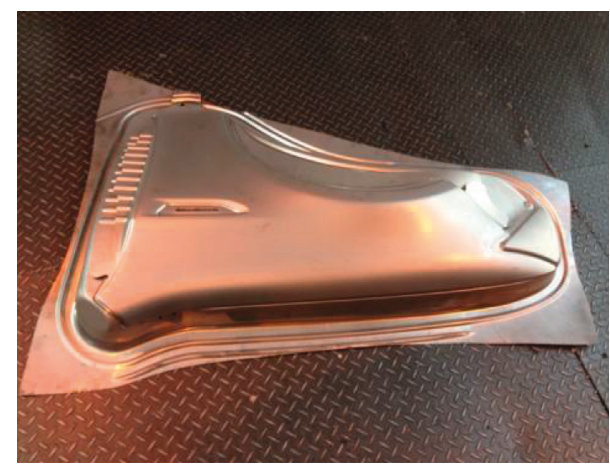

FIgURE 10: Fender product diagram.

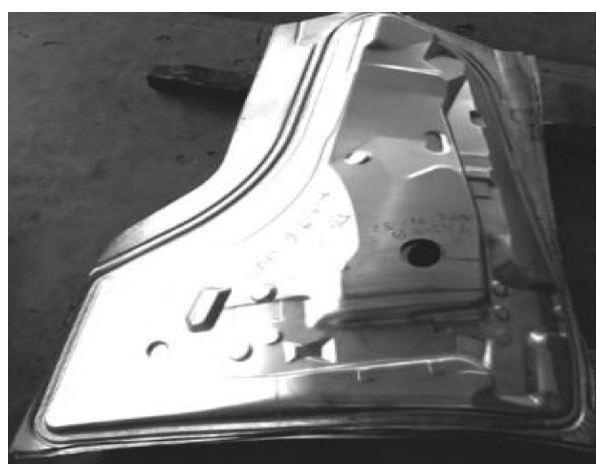

Figure 11: Pixel point spraying on the fender. processing and data analysis. Due to the large size of the panel parts, in order to make the molding margin data more accurate, before taking the photo of the panel parts, it is necessary to evenly spray black pixels on the surface of the products stamped by the panel and carry out dot matrix processing on the surface of the products [15]. Coordinate blocks are uniformly arranged on the fender with good black uniform pixel points. Through the positioning of coordinate blocks, the plates with different positions are placed in the same coordinate system so that the margin data will not produce deviation. The fender lattice is shown in Figure 11. Take photos of the fender parts after lattice, import all photos into ARGUS software, and finally get the complete mold figure of the fender. The mold figure is similar to that in DYNAORM. After importing the raw material parameters of DC04 of the fender into ARGUS software, the formation limit diagram of FLC of the fender as shown in Figure 12 is generated. In Figure 12, 16 position points are selected for investigation. The rate of metal change at each point is shown in Table 10.

As can be seen from the FLC forming limit diagram of the fender, the surface of the fender is green, which indicates that the material thickness change rate of each part of the finished fender is within the safe range after the deep drawing process [16]. According to the structural characteristics of the fender and its assembly mode, take investigation points at the corners of step surfaces and the installation places of headlights where quality problems such as sliding and cracking are easy to occur. By analyzing the forming margin of these locations where the stress is complex and prone to critical deformation, we can observe whether the overall forming margin of the fender is within the safety margin. The FLC molding margin in the ARGUS postprocessing module is shown in Figure 13.

It can be seen from Figure 13 that, under the combined action of primary and secondary strains, the 16 reference points obtained for the fender are all below the FLC failure line; the 16 observed forming points are all within the green range below the FLC failure line. Through these 16 points, the forming margin of the fender under critical conditions was investigated. The critical points molding margin are in the safe range, so the overall molding margin of the fender is also in the safe range [17]. Install the fender to the fender fatigue tester, fix the locating hole and the lamp mounting

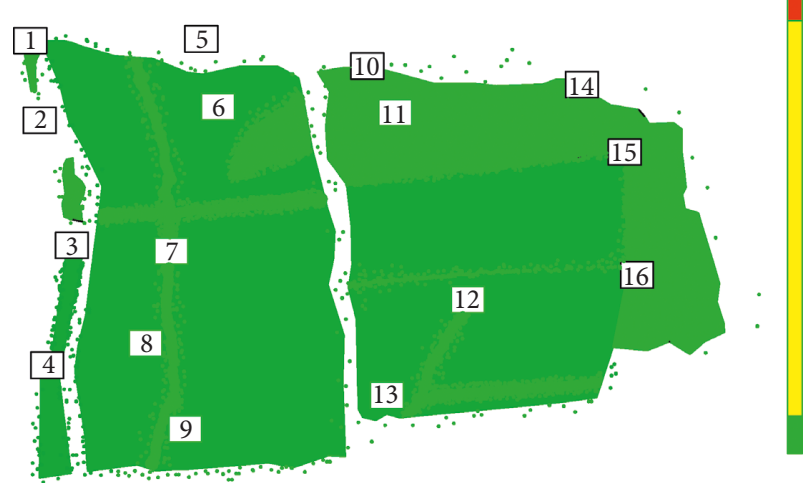

Figure 12: FLC forming limit diagram of fender.

TABLE 10: Rate of metal change at each point.

\begin{tabular}{lc}
\hline Test point & Rate of metal change $(\%)$ \\
\hline 1 & -18.580 \\
2 & -24.765 \\
3 & -21.874 \\
4 & -21.935 \\
5 & -5.580 \\
6 & -19.979 \\
7 & -21.308 \\
8 & -21.874 \\
9 & -7.034 \\
10 & -5.650 \\
11 & -4.650 \\
12 & -23.559 \\
13 & -23.651 \\
14 & -23.168 \\
15 & -22.365 \\
\hline
\end{tabular}

hole on the parts, and connect the measuring fixture with the fender to test the shear strength tester. The fender fatigue tester is started in the vertical direction $\pm 10 \mathrm{~mm}$, and 150 cyclic shear strength tests are performed. The information of the common vibration point in the resonance test of the sweep frequency test piece of the fender is shown in Table 11. At $80^{\circ} \mathrm{C}$, the resonance sweep test control curve of the frequency sweep test article of the fender and the resonance sweep test response curve of the frequency sweep test article of the fender are shown in Figures 14 and 15, respectively. 


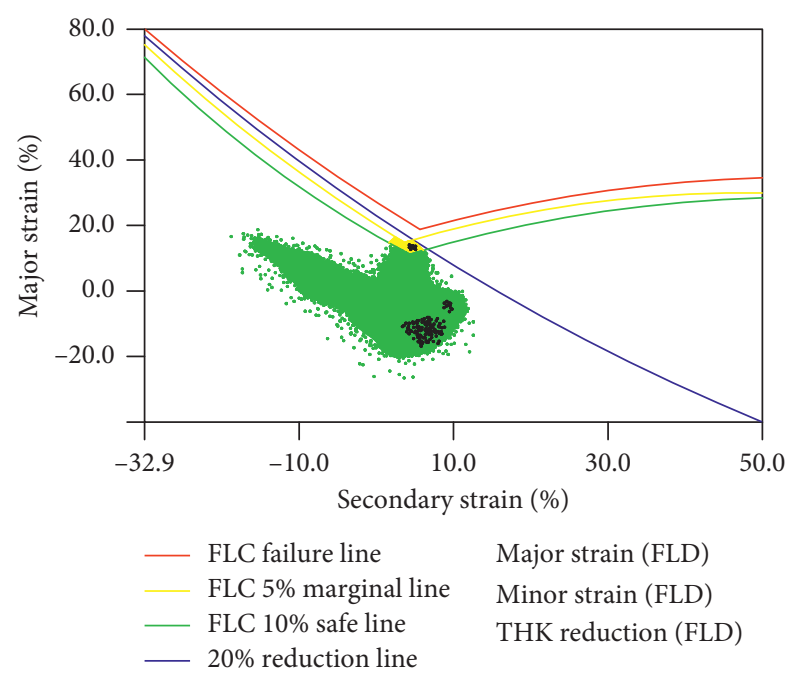

Figure 13: Fender forming margin diagram.

TABLE 11: Information of 16 test points.

\begin{tabular}{lcc}
\hline Test point & Frequency $(\mathrm{HZ})$ & Peak acceleration $(\mathrm{g})$ \\
\hline 1 & 52.8202 & 9.1526 \\
2 & 52.8202 & 5.25275 \\
3 & 52.8202 & 10.1172 \\
4 & 52.8202 & 9.60409 \\
5 & 52.8202 & 9.23014 \\
6 & 52.8214 & 6.6547 \\
7 & 52.8196 & 9.1254 \\
8 & 52.8202 & 10.6589 \\
9 & 52.8201 & 11.2357 \\
10 & 52.8202 & 6.7952 \\
11 & 52.8202 & 8.2132 \\
12 & 52.8202 & 6.2558 \\
13 & 52.8010 & 9.6541 \\
14 & 52.8202 & 12.9512 \\
15 & 52.8202 & 13.2266 \\
16 & 52.8202 & 8.6988 \\
\hline
\end{tabular}

The natural frequency of the fender is $52.8 \mathrm{HZ}$, which is higher than the $33 \mathrm{HZ}$ standard in the automobile industry. The result is obviously outside the range of the resonance point, indicating that the test result is qualified.

\section{Summary}

In this paper, the parameter optimization of the stamping process of fender is studied, orthogonal test is designed, and the order of factors affecting the quality and performance of the die forming is obtained. Taguchi method is used to optimize the process parameters of the fender, and the results show that

(1) Formulate the stamping process of the fender, carry out the drawing and forming design of the automobile fender, use DYNAFORM to simulate and analyze the final scheme, and determine the rationality of the fender forming scheme.

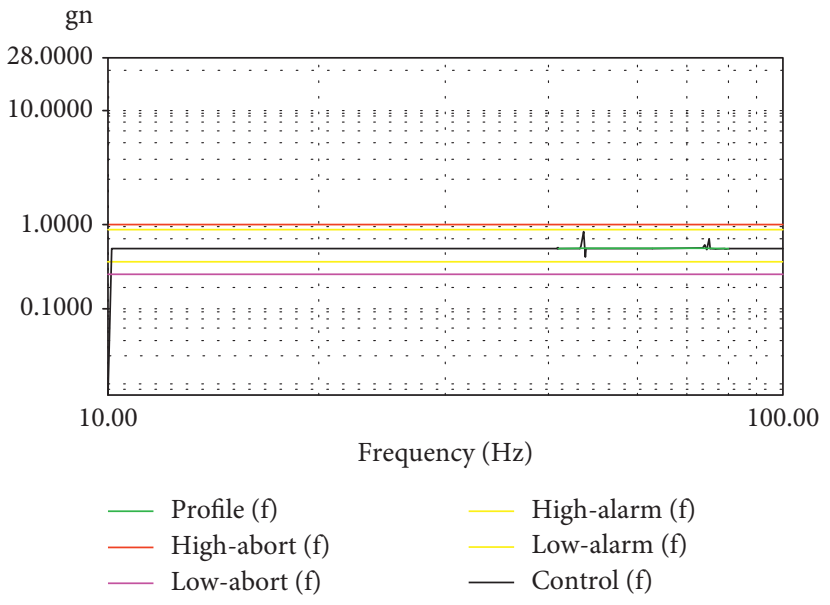

FIGURE 14: Frequency control curve.

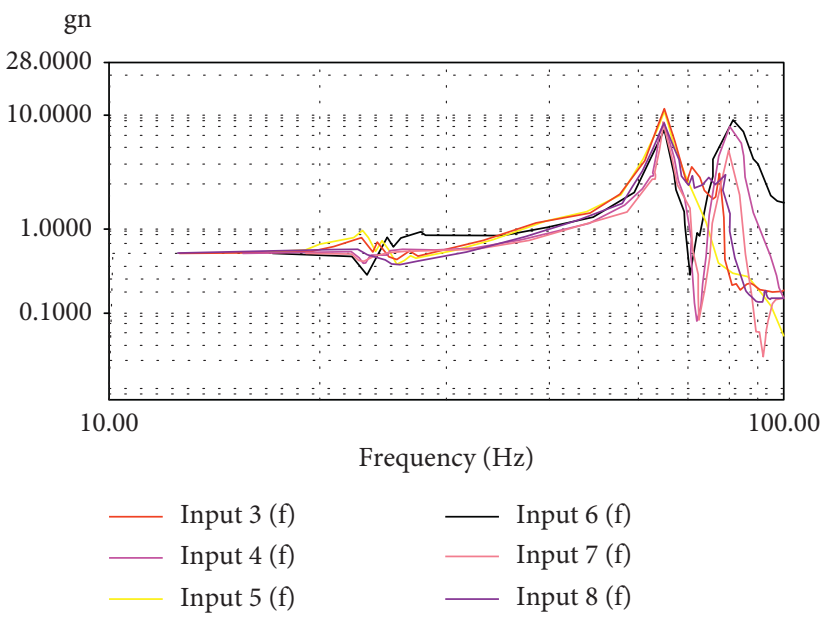

FIGURE 15: Frequency response curve.

(2) Based on the numerical simulation of drawing and forming of automobile fender, four technological parameters such as friction coefficient, blank holder force, die clearance, and radius of die are selected as factors, and the evaluation indexes of fender stamping and forming are determined as maximum thinning rate and maximum thickening rate. The orthogonal table is designed, and the orthogonal test is carried out on the stamping forming of fender. Through the data analysis of the simulation test results, the influence trend of these four factors on the quality of automobile fender stamping molding is obtained, and the optimal technological parameters are obtained.

(3) Taguchi method is used to analyze the variance of the SNR of each factor at each level and determine the best level after screening out the stable factors. On this basis, the adjustable factors are optimized to obtain the most robust combination of molding process parameters. The optimum technological parameters are as follows: blank holder force is 
$120 \mathrm{KN}$, die clearance is $1.0 \mathrm{t}$, friction coefficient is 0.11 , and radius of die is $6 \mathrm{~mm}$. The experimental results show that the optimum parameters are correct.

\section{Data Availability}

The data used to support the findings of this study are included within the article.

\section{Conflicts of Interest}

The authors declare that they have no conflicts of interest.

\section{Acknowledgments}

This article belongs to the major projects of the "Natural Science Foundation of Anhui Province Education Department (KJ2016SD05 and KJ2017ZD12)." This article belongs to the project of the "Wuhu Scientific Research Project (2016cxy01)."

\section{References}

[1] L. Zhang, C. Lei, and F. Wang, "Numerical simulation of sheet metal superplastic drawing process," Metal Forming Process, vol. 18, no. 1, p. 29-34, 2002.

[2] G. Ma, B. Huang, C. Su et al., "Simulation and optimization of process parameters for drawing and forming of automobile fender," Forging \& Stamping Technology, vol. 40, no. 3, p. 19-22, 2015.

[3] G. Ma, Finite Element Simulation Research and Process Parameter Optimization of Automobile Cover Stamping, Shandong University of Science and Technology, Qingdao, China, 2015.

[4] X. Liu and W. Huang, "Simulation study on drawing forming of automobile covering parts based on DYNAFORM," Hot Working Process, vol. 42, no. 3, pp. 129-131, 2013.

[5] J. H. Kim, S. I. Oh, and S. Kobayashi, "Analysis of stretching of sheet metals with hemispherical punch," International Journal of Machine Tool Design and Research, vol. 18, no. 4, pp. 209-226, 1978.

[6] Z. Meng, Z. Zhang, and H. Zhou, "A novel experimental data-driven exponential convex model for reliability assessment with uncertain-but-bounded parameters," Applied Mathematical Modelling, vol. 77, pp. 773-787, 2020.

[7] C. H. Toh and S. Kobayashi, "Deformation analysis and blank design in square cup drawing," International Journal of Machine Tool Design and Research, vol. 25, no. 1, pp. 15-32, 1985.

[8] R. Liu, Y. Zhang, C. Wen et al., "Orthogonal experiment design and analysis method research," Testing Technology and Management, vol. 27, no. 9, pp. 52-55, 2010.

[9] S. Fu, S. Fang, and Z. Wang, "Simulation design of GPS microstrip antenna based on taguchi optimization method," Journal of Microwave, vol. 28, no. 3, pp. 33-38, 2012.

[10] Y. Wang and S. Xiao, Quality Improvement Planning and Implementation, China Economic Press, Beijing, China, 2005.

[11] B. Hu, Q. Zhang, X. Zhao et al., "Research on optimization design of CRT thermal explosion cutting equipment based on taguchi method," Machinery Design and Manufacture, vol. 5, pp. 15-17, 2010.
[12] G. Taguchi, E. Elsayed, and T. Hsiang, "Quality engineering in production systems," Journal of Materials Processing Technology, vol. 48, pp. 151-157, 1995.

[13] B. D. Youn, K. K. Choi, and Y. H. Park, "Hybrid analysis method for reliability-based design optimization," Journal of Mechanical Design, vol. 125, no. 2, pp. 221-232, 2003.

[14] C. Yan, W. Cai, and Y. Cai, "Optimization of multi-index injection molding process parameters based on CAE and orthogonal test," Engineering Plastics Application, vol. 38, no. 4, pp. 36-38, 2010.

[15] Z. Meng and B. Keshtegar, "Adaptive conjugate single-loop method for efficient reliability-based design and topology optimization," Computer Methods in Applied Mechanics and Engineering, vol. 344, pp. 95-119, 2019.

[16] Z. Meng, D. Zhang, G. Li, and B. Yu, “An importance learning method for non-probabilistic reliability analysis and optimization," Structural and Multidisciplinary Optimization, vol. 59, no. 4, pp. 1255-1271, 2019.

[17] A. Mardin, G. Ida, and J. Per, "Use and knowledge of robust design methodology: a survey of Swedish industry," Journal of Engineering Design, vol. 14, no. 2, pp. 129-143, 2003. 


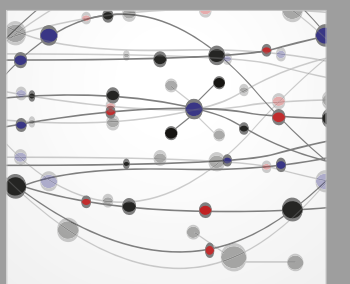

The Scientific World Journal
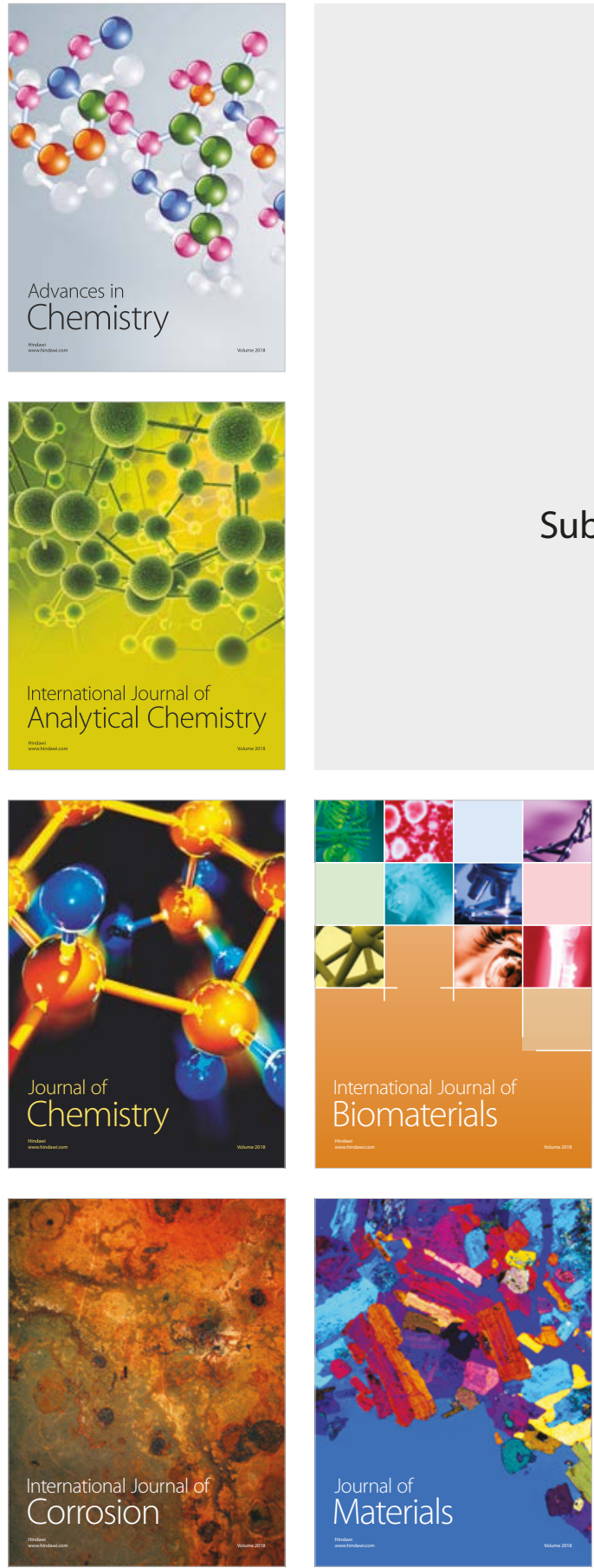

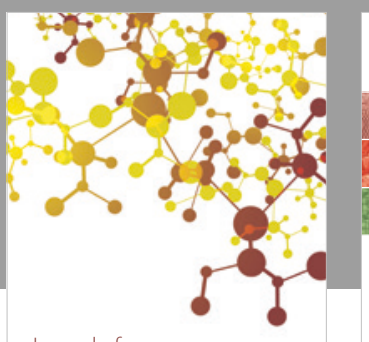

Journal of

Applied Chemistry
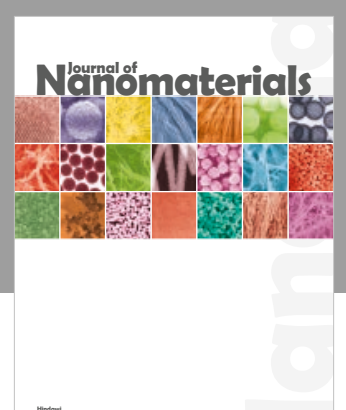

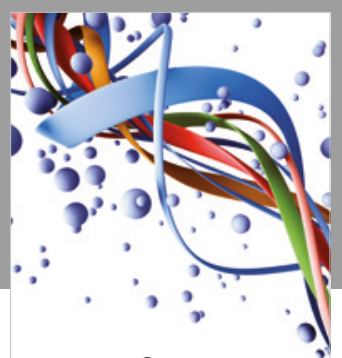

Scientifica

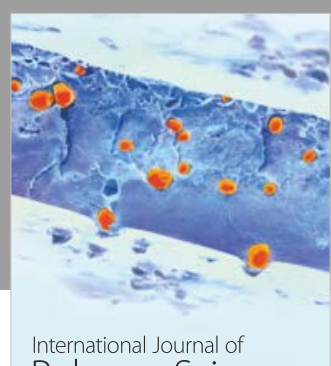

Polymer Science

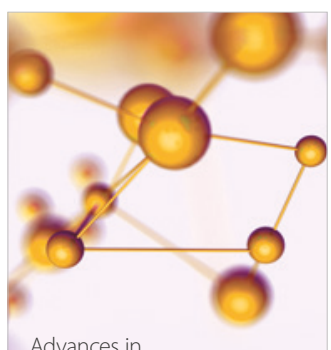

Physical Chemistry
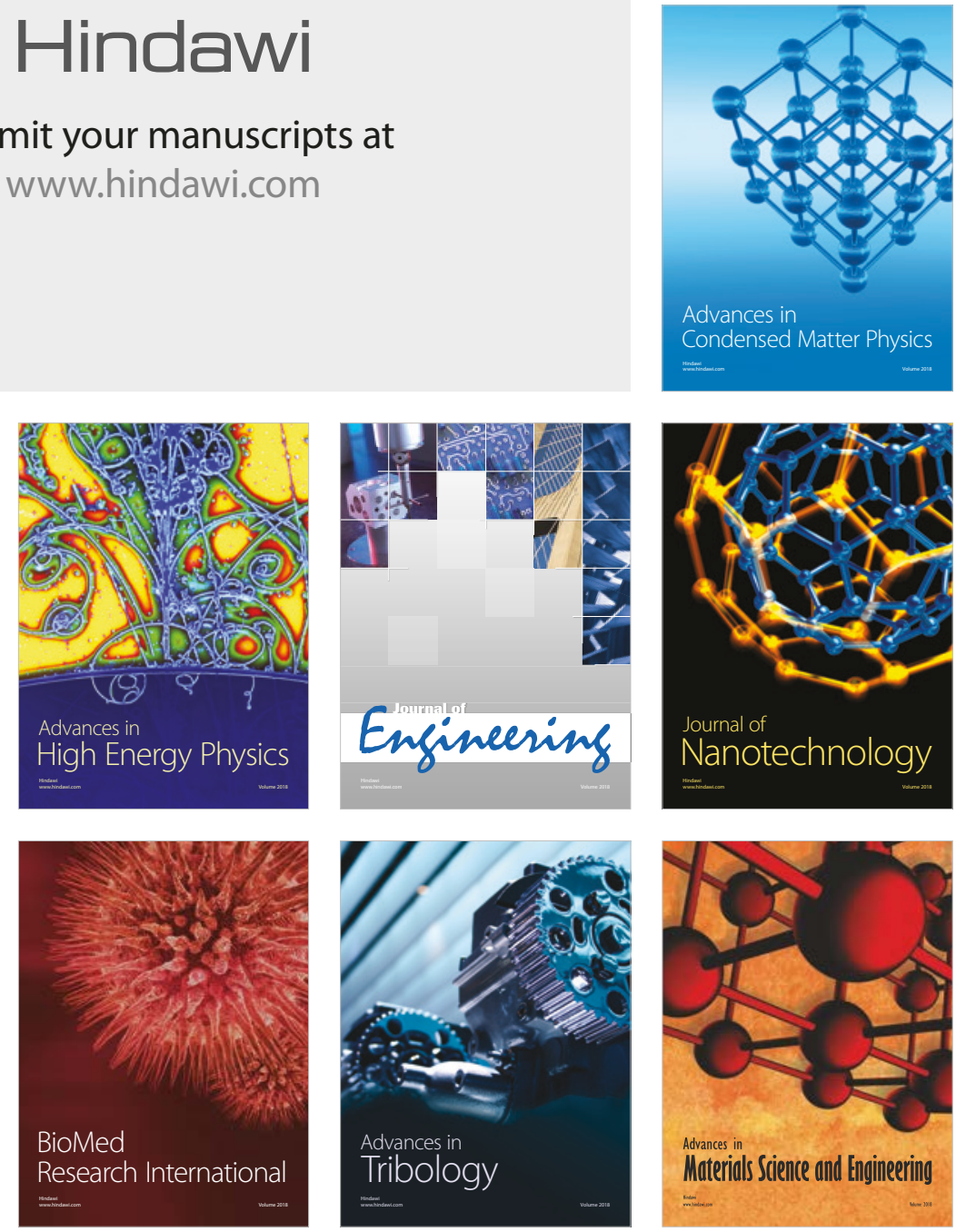